\title{
DO PRODUTIVISMO, AO NEOPRODUTIVISMO, PARA O PÓS-PRODUTIVISMO: perspectivas teóricas recentes na interpretação das mudanças no espaço rural e elucidação de práticas inovadoras
}

\author{
FROM PRODUCTIVISM, TO NEOPRODUTIVISM, FOR \\ POST-PRODUCTIVISM: recent theoretical perspectives in the \\ interpretation of changes in rural and elucidation of innovative \\ practices
}

\author{
Valdir Roque Dallabrida \\ Universidade do Contestado - Canoinhas - SC - Brasil \\ Eliziane Luiza Benedetti \\ Instituto Federal de Educação, Ciência e Tecnologia - Canoinhas - SC - Brasil
}

\begin{abstract}
Resumo: Apesar da hegemonia das abordagens e práticas predominantemente produtivistas, nas últimas décadas, o espaço rural tem começado a ser pensado na perspectiva da valorização dos recursos e ativos do território, considerando suas especificidades, da preservação dos recursos naturais, das tradições e saber-fazer local e da manutenção da biodiversidade (vegetal, animal e cultural), com um mínimo de autonomia. Tais perspectivas podem ser consideradas um primeiro passo rumo à multifuncionalidade ou pluriatividade da agricultura, na forma de sistemas produtivos agroecológicos e diversificados, o que se considera possibilidades de superação de práticas produtivistas. Com o propósito de identificar como a literatura tem tratado o referido tema, este texto, na forma de ensaio teórico, contribui para o registro do estado da arte. Considerando-se a literatura, vislumbram-se perspectivas de práticas pós-produtivistas, no entanto, muito mais como possibilidade, sendo as experiências práticas ainda restritas.
\end{abstract}

Palavras-Chave: Produtivismo. Pós-Produtivismo. Espaço Rural. Desenvolvimento Territorial. Agroecologia. Multifuncionalidade.

\begin{abstract}
Despite the hegemony of approaches and predominantly productivist practices in recent decades rural areas have begun to be thought of from the perspective of development of resources and assets of the territory, considering its specific characteristics, the preservation of natural resources, tradition and know where and maintaining biodiversity (plant, animal and cultural), with a minimum of autonomy. Such prospects can be considered a first step toward multifunctionality or pluriactivity, in the form of agroecological and diversified production systems, which consider possibilities of overcoming productivist practices. In order to identify how the literature has treated the said topic, this text, in the form of theoretical essay contributes to the record of the state of the art. Considering the literature, to envision perspective post-productivists practice, however, much as possible, and practical experiences remain restricted.
\end{abstract}

Keywords: Productivism. Post-Productivism. Rural space. Territorial Development. Agroecology. Multifunctionality.

\section{Introdução}

O desafio da superação das mazelas provocadas pelas mudanças impingidas ao espaço rural desde a chamada Revolução Verde e a perspectiva de aumento da demanda por produtos oriundos de processos de produção sustentáveis (nos aspectos econômico, social, cultural e ambiental), transcendendo os sistemas produtivos de caráter 
produtivistas, plenamente consolidados, levaram, nas últimas décadas, muitos cientistas e pesquisadores a estruturar uma base teórica capaz de interpretar tais processos.

Sob o ponto de vista teórico, a literatura faz referência a enfoques, tais como: Multifuncionalidade ou Pluriatividade da Agricultura, Sistemas Agroalimentares Localizados, Sistemas Agroflorestais, Cestas de Bens e Serviços com Identidade Territorial, Territórios-Rede e Ator-Rede e Agroecologia e Desenvolvimento Territorial. As práticas que se enquadram em tais enfoques teóricos costumam ser denominadas pós-produtivistas.

Portanto, a atenção incide sobre um conjunto de abordagens teóricas que convergem minimamente com a perspectiva de superação de práticas produtivistas que podem (ou não) transitar pelo neoprodutivismo, visando práticas pós-produtivistas. Convém que tais práticas se coadunem também com a valorização dos recursos e ativos do território, considerando as especificidades, a preservação e revalorização dos recursos naturais, a manutenção da biodiversidade (vegetal, animal e cultural), as tradições e saber-fazer local, com um mínimo de autonomia.

No entanto, esse novo olhar ao meio rural brasileiro ainda é recente. A grande importância econômica que a agricultura produtivista brasileira possui (principalmente pela exportação de commodities), faz com que os incentivos, tanto financeiros como por meio de políticas públicas, não atenda satisfatoriamente a demanda do setor com foco na produção pós-produtivista. Dessa forma, a resistência a esse modelo por parte dos produtores ainda persiste. Porém, as várias alternativas aqui apresentadas demonstram que a agricultura pós-produtivista é viável e merece ser incentivada, pois se apresentam como práticas inovadoras que convergem para o desenvolvimento sustentável.

\section{Procedimentos metodológicos}

O presente texto integra-se a dois processos de investigação: (a) execução de projeto de pesquisa com aporte de recursos provenientes do Papel dos atores sociais na aquisição de produtos da agricultura familiar para alimentação...Conselho Nacional de Desenvolvimento Científico e Tecnológico - CNPq (Signos Distintivos Territoriais e Indicação Geográfica); (b) plano de atividades de estágio pós-doutoral ${ }^{1}$.

Metodologicamente, o texto resulta de estudos teóricos e ampla consulta bibliográfica, além de observações de campo, portanto, priorizando enfoque metodológico de caráter teórico ensaísta.

Os estudos teóricos propuseram-se a revisar a literatura contemporânea, dando destaque aos enfoques que pudessem servir como um marco teórico que pudessem orientar e/ou interpretar os esforços mundiais no sentido de pensar e/ou propor novos processos e práticas no espaço rural, em especial voltadas à chamada agricultura familiar. Denominaremos, neste texto, tais enfoques de pós-produtivistas ${ }^{2}$.

Inicia-se a revisão da literatura com uma abordagem sobre o estado da arte dos sistemas Produtivistas, Neoprodutivista e Pós-produtivista. Em seguida, os processos de gestão e práticas inovadoras na agricultura familiar são apresentadas dando ênfase nas

\footnotetext{
${ }^{1}$ Tema dos estudos no Estágio Pós-Doutoral: Contribuição ao desenvolvimento territorial através da avaliação nutricional de solos e plantas de ervais nativos, como estímulo à produção orgânica sustentável, no Planalto Norte Catarinense, onde os autores deste texto são, respectivamente, orientador e orientada.

${ }^{2}$ Sabemos que há críticas ao que se convencionou chamar de pós-produtivismo. O termo é aqui utilizado com o sentido de abarcar enfoques teóricos que propugnem práticas e processos de superação do produtivismo no espaço rural.
} 
cooperativas descentralizadas, produção agroecológica e em sistemas agroflorestais, além da especificação de ativos e recursos territoriais.

\section{Enfoques teóricos}

As abordagens teóricas utilizadas para referenciar as mudanças ocorridas no espaço rural - no decorrer das últimas décadas - em geral, utilizam categorias teóricas tais como produtivismo, neoprodutivismo e/ou pós-produtivismo.

\subsection{Do produtivismo, ao neoprodutivismo, para o pós-produtivismo no espaço rural: revisão do estado da arte ${ }^{3}$}

A literatura que trata das mudanças ocorridas no espaço rural, tanto as abordagens teóricas quanto os estudos de caso, provém preponderantemente de países europeus, principalmente França, Reino Unido e Espanha. Informações referentes ao Brasil são abordadas por um pequeno número de autores, dentre os quais, Dufumier e Couto (1998), que apresentam as mudanças do produtivismo para o neoprodutivismo no país.

As atividades desenvolvidas pelo setor agrário mundial, durante muito tempo, foram voltadas basicamente para produção de alimentos. Dessas características surgiu o modelo produtivista. Nesse modelo, predomina a agricultura intensiva, que contou com o apoio do Estado na sua implantação e tem como principal objetivo a produção e a produtividade (LOWE et al., 1993). Esses aspectos refletem na realidade vivenciada pela União Europeia, onde os subsídios, principalmente governamentais, direcionados à agricultura produtivista, sempre foram superiores quando comparados aos recursos destinados para agricultura alternativa (CAZELLA e ROUX, 1999). No Brasil, esse panorama não difere. Além disso, investimentos governamentais à produção sustentável no país são recentes. Somente em torno do ano 2000, o governo federal instituiu o Ministério do Desenvolvimento Agrário - MDA e uma linha de crédito nacional para apoiar os agricultores familiares (LAMINE, 2015), cujas propriedades caracterizam-se pela concentração da produção agroecológica, com base nos princípios da sustentabilidade.

Como ocorreu em outros países, no Brasil, o maior incentivador do sistema produtivista no espaço rural foi o Estado, situação que trouxe consequências para a agricultura, como, por exemplo, a degradação ambiental (KNICKEL, 1990).

$\mathrm{O}$ resultado do produtivismo é comprovado facilmente nas paisagens rurais, com as terras sendo usadas para produzir quantidades enormes de alimentos e florestas sendo destinadas às indústrias com alta capacidade produtiva (BERGSTROM, 2002). Nesse modelo, os estabelecimentos agrícolas especializam-se na produção de poucas variedades de mercadorias, em substituição ao sistema de diversificação. O agricultor utiliza, cada vez mais, insumos industriais, e pratica a venda para o mercado, em detrimento do autoconsumo, além da substituição dos conhecimentos tradicionais pelos conhecimentos técnicos e padronizados (DUFUMIER e COUTO, 1998).

No entanto, mudanças ocorreram nesse sistema de produção, propiciando novas perspectivas para o meio rural. A transição pós-produtivista significa uma progressiva mudança das tendências e das características apresentadas para definir o desenvolvimento agrário, manifestando-se desde a Segunda Guerra Mundial até os anos 1980 (ILBERY e BOWLER, 1998), perpassando pelo neoprodutivismo, que resulta da diversificação de modelos nos quais se embasa o desenvolvimento agrícola desde a crise

\footnotetext{
${ }^{3}$ Essa parte do texto retoma abordagem feita em Dallabrida, Benedetti e Tomporoski (2016).
} 
do produtivismo (DUFUMIER e COUTO, 1998), culminando com o pós-produtivismo, modelo no qual prevalecem como principais características a qualidade $\mathrm{e}$ multifuncionalidade da agricultura (ILBERY e BOWLER, 1998).

As preocupações sobre a autossuficiência, no período pós Segunda Guerra Mundial, foram substituídas por preocupações sobre a gestão e eliminação de excedentes de alimentos, os custos de subsídios agrícolas e os problemas ambientais decorrentes da agricultura intensiva (WARD et al., 2008).

No entanto, em meados da década de 1980, ocorreram mudanças no setor agrário, que resultaram na introdução do conceito de pós-produtivismo. Esse conceito incorpora as novas funções da agricultura, no que se refere à diversificação da economia rural com atividades relacionadas principalmente ao setor terciário, resultando no que tem sido denominado de agricultura multifuncional, multidimensional e polivalente (ARMESTO LÓPEZ, 2005).

Vários termos são usados para caracterizar o pós-produtivismo, tais como: regime de agricultura multifuncional (WILSON, 2001); modernização ecológica (EVANS et al., 2002); agricultura multifuncional (BJÖRKHAUG e RICHARDS, 2007) e multifuncionalidade (ROCHE e ARGENT, 2015). Entretanto, observa-se que apenas a nomenclatura difere, visto que as características que os termos expressam são similares.

As melhores caracterizações do pós-produtivismo foram apresentadas e discutidas por Ilbery e Bowler (1998), Wilson (2001) e Evans et al. (2002). No Quadro 1, são evidenciadas as principais obras que destacam algumas características (e/ou propostas) do pós-produtivismo.

Ilbery e Bowler (1998) destacam as três dimensões da mudança, que consistem na substituição da intensificação pela extensificação, da concentração pela dispersão e da especialização pela diversificação. De acordo com esses autores, a extensificação diminui os níveis de poluição ambiental e restaura os habitats naturais. Acerca da dispersão, a subdivisão da propriedade em unidades menores possibilita dispersar a produção agrícola e reduzir a produção concentrada em poucas fazendas de grande porte. A diversificação, em detrimento da especialização, caracteriza-se pela pluriatividade, pela possibilidade da prática do turismo rural e outras formas de recreação no espaço rural.

Conforme Wilson (2001), o conceito de pós-produtivismo deve considerar aspectos ambientais, econômicos, sociais e culturais. Em sua obra, faz um comparativo entre as características do produtivismo com o pós-produtivismo, em relação à ideologia, atores envolvidos, regime alimentar, às políticas agrícolas, às técnicas de cultivo e aos impactos ambientais. Além disso, Evans et al. (2002) destacam cinco categorias para caracterizar o pós-produtivismo, sendo: a mudança da produção focada na quantidade para a qualidade dos alimentos, pluriatividade, promoção de agricultura sustentável por meio de políticas agro ambientais, dispersão de padrões de produção e reestruturação do apoio do governo para a agricultura.

Quadro 1. Quadro síntese com as principais obras, categoria conceitual utilizada e características e/ou propostas para agricultura pós-produtivista

\begin{tabular}{|l|l|l|}
\hline Autor(es)/obra(s) & \multicolumn{1}{|c|}{$\begin{array}{c}\text { Categoria conceitual } \\
\text { utilizada (proposta) }\end{array}$} & $\begin{array}{c}\text { Características e/ou propostas para agricultura } \\
\text { pós-produtivista }\end{array}$ \\
\hline $\begin{array}{l}\text { Evans e Ilbery } \\
(1993)\end{array}$ & $\begin{array}{l}\text { Multifuncionalidade do } \\
\text { espaço rural }\end{array}$ & $\begin{array}{l}\text { Propõem a utilização da agroecologia e a } \\
\text { multifuncionalidade dos espaços rurais }\end{array}$ \\
\hline $\begin{array}{l}\text { Ilbery e Bowler } \\
(1998)\end{array}$ & Pluriatividade & $\begin{array}{l}\text { Diminuição da poluição, dispersão da produção e } \\
\text { estímulo ao turismo rural }\end{array}$ \\
\hline $\begin{array}{l}\text { Cazella e Roux } \\
(1999)\end{array}$ & Multifuncionalidade & $\begin{array}{l}\text { Qualidade dos alimentos, proteção do meio } \\
\text { ambiente e valorização dos diferentes tipos de } \\
\text { territórios }\end{array}$ \\
\hline
\end{tabular}




\begin{tabular}{|l|l|l|}
\hline Wilson (2001) & Agricultura multifuncional & Agricultura com respeito ao meio ambiente \\
\hline Evans et al. (2002) & Modernização ecológica & $\begin{array}{l}\text { Foco na produção de alimentos de qualidade e uma } \\
\text { agricultura sustentável ambientalmente }\end{array}$ \\
\hline $\begin{array}{l}\text { Armesto López } \\
(2005)\end{array}$ & $\begin{array}{l}\text { Multifuncionalidade da } \\
\text { agricultura }\end{array}$ & $\begin{array}{l}\text { Qualidade do alimento deverá substituir a busca } \\
\text { pelo aumento de produção }\end{array}$ \\
\hline
\end{tabular}

Fonte: Elaboração própria

As novas funções da agricultura se encontram entre as atividades precípuas para o desenvolvimento rural (CAZELLA e ROUX, 1999), sendo que houve várias tentativas de definir a diversificação no meio rural (ILBERY, 1991). Considerando esse aspecto, a partir daqui, caracterizar-se-á algumas dessas atividades.

Para isso, inicialmente, será necessário caracterizar desenvolvimento rural. Ploeg et al. (2000) consideram o desenvolvimento rural como uma combinação entre forças internas e externas de determinada região, onde atores das áreas rurais se envolvem na criação de novos produtos e serviços, tendo em vista novos mercados, buscando reduzir custos a partir da implementação tecnológica. Além disso, Ilbery et al. (2005) destacam que, em debates sobre desenvolvimento rural, tem-se defendido a mudança paradigmática do modelo produtivista para outro modelo, visando, entre outras transformações, reconectar a produção ao consumo de alimentos.

Partindo da premissa de que o desenvolvimento rural contempla a criação de novos produtos e serviços (PLOEG et al., 2000), obtem-se as novas funções da agricultura ou as novas tendências da agricultura pós-produtivista.

Esse enfoque pós-produtivista, com o uso do termo multifuncionalidade da agricultura, é defendido por Armesto López (2005), tratando a qualidade como elemento chave da nova agricultura, pretendendo substituir a busca pelo aumento de produção. Hervieu (1996) também relata essa nova preocupação ao afirmar que a noção de qualidade é tão importante para a década em que vivemos como a quantidade foi para o período do pós-guerra.

A qualidade é uma das características mais importantes no regime pósprodutivista. A busca dessa característica é impulsionada pelo aumento da demanda dos consumidores por produtos saudáveis e de qualidade (ILBERY e BOWLER, 1998; WILSON, 2001; ARMESTO LÓPEZ, 2005; MATHER et al., 2006), sendo que a percepção da qualidade integra um processo no qual o consumidor exige certas características que considera relevantes a um produto, como peculiaridades do processo de produção e certificação (ILBERY e KNEAFSEY, 2000).

Cazella e Roux (1999) também usam o termo multifuncionalidade para caracterizar o conjunto de ações relacionadas às atividades agrícolas que tratam da qualidade dos alimentos, a proteção do meio ambiente e a valorização dos diferentes tipos de territórios, além de considerarem a agricultura multifuncional um importante mecanismo no processo de vitalização rural. Armesto López (2005) inclui, além da qualidade, a proteção à biodiversidade e às paisagens rurais e a geração de emprego como características de multifuncionalidade. Características defendidas por Cazella e Roux (1999) consideram esse tipo de agricultura uma possibilidade para inserção social e profissional, com a alocação dos membros da unidade familiar tendendo a destacar a agricultura nas estratégias de desenvolvimento rural ${ }^{4}$.

Destacando o conceito de agricultura dual, Abramovay (1994) enfatiza que esse tipo de agricultura se apresenta como uma forma de resolver, ao mesmo tempo, os problemas de preservação do meio ambiente e a redução dos excedentes agrícolas. A agricultura dual é caracterizada por uma minoria de agricultores produtivistas,

\footnotetext{
${ }^{4}$ O tema multifuncionalidade da agricultura é tratado também em: Bonnal; Cazella; Maluf, 2008; Cazella; Bonnal; Maluf, 2009 e Vieira et al., 2010.
} 
responsáveis pela maior parcela da produção agropecuária e, ao lado desses, os agricultores "jardineiros da natureza", cuja principal função social é cuidar da paisagem e garantir a integridade do território.

De acordo com Ilbery e Kneafsey (2000, p.219), dentre os parâmetros que contribuem especificamente para a consolidação do sistema de qualidade, destacam-se a certificação do produto por uma entidade externa, a vinculação do produto com o território, a especificidade dos meios de produção utilizados e a atratividade do produto para o consumidor.

Em relação à vinculação do produto com o local de origem, destaca-se a aproximação do consumidor ao produtor. Contudo, essa aproximação não diz respeito somente ao tempo e à distância percorrida pelo produto, e sim às informações contidas no produto, tais como o local de produção, manejo adotado, pessoas envolvidas (TRICHES e SCHNEIDER, 2015), além de processos culturais e tradicionais utilizados (PULPÓN, 2013), o que gera uma sensação de identificação do consumidor para com o produtor, além da possibilidade de distinção entre produtos, passando maior confiabilidade ao consumidor.

O consumidor deve ser um agente ativo para a implementação de um novo modelo agroalimentar, no qual o consumo deve estar envolvido em novas dinâmicas e políticas que remetem a valorações do local, à qualidade dos alimentos e à relação do meio urbano com o meio rural (TRICHES e SCHNEIDER, 2015). Além disso, também há a possibilidade de uma aproximação mais efetiva entre esses dois atores da cadeia produtiva, desde que haja uma estrutura para receber os consumidores no local de produção. Para que se efetive esse tipo de atividade, outras atrações devem ser implementadas, como artesanato, comidas típicas, passeios, etc.

Considerado que amiúde a renda gerada pela agricultura é insuficiente, uma reestruturação contemporânea pode ser vantajosa, pois envolve uma mudança da produção agrícola para uma ampla gama de atividades não agrícolas (EVANS e ILBERY, 1993).

Dessa forma, as mudanças pós-produtivistas instigam a ponderar o meio rural não apenas como local para produção de alimentos, e sim um espaço onde podem ser exploradas diversas aptidões, aliada à implementação de uma agricultura sustentável, a qual preconiza a prática de uma agricultura que responda às necessidades atuais, sem colocar em risco os recursos naturais para as gerações futuras. Portanto, a sustentabilidade da propriedade agrícola também precisa ser considerada. Assim, concorda-se com Landais (1998) quando afirma que a efetiva sustentabilidade de uma propriedade agrícola é alcançada quando se contempla os componentes econômico, social, intergeracional e o meio ambiente dentro da propriedade.

\section{Processos de gestão e práticas inovadoras na agricultura familiar}

As práticas produtivistas no espaço rural, historicamente e hodiernamente, resultaram em significativos impactos espaciais, como o uso intensivo dos solos, a ampliação das áreas de cultivo agrícola pela concentração das propriedades, com consequências sociais (êxodo rural) e ambientais (contaminação com agrotóxicoagroquímicos) decorrentes. Outra característica desse modelo de produção consiste na subordinação do produtor ao setor comercial e industrial, representado predominantemente pelas empresas do agronegócio. Mesmo as cooperativas tradicionais que atuam no setor, em pouco se diferenciam. Ambos os fatores atuam impondo uma dinâmica produtiva própria, seja pelo fornecimento de pacotes 
tecnológicos, seja pelo controle dos insumos e da compra da matéria-prima, suprimindo a autonomia dos produtores.

No caso das práticas agrícolas do tipo familiar, os impactos são mais perceptíveis, provocando intensos processos de êxodo rural. E a questão da subordinação e falta de qualquer tipo de autonomia atinge graus tais que se caracterizam como o máximo de fragilização de relações de trabalho, próximas à escravidão.

Mas em algumas regiões em que predomina a produção agrícola em pequenas propriedades, e do tipo familiar, já foram pensadas estruturas cooperativas de armazenamento, industrialização e comercialização. Um exemplo, ao qual far-se-á menção a seguir, é a experiência das cooperativas descentralizadas da agricultura familiar.

\subsection{A experiência das cooperativas descentralizadas}

Os desafios que pretendem enfrentar as cooperativas descentralizadas poderiam ser resumidos em três variáveis: (i) a subalternidade, ou seja, a subordinação do produtor ao setor comercial e industrial; (ii) a verticalização do processo produtivo, ou seja, sistemas de gestão do processo produtivo hierárquicos, impositivos, sem margem para interferência do produtor; (iii) relação sociedade-natureza predatória, por exemplo, pela predominância de práticas de contaminação de solos e água, de redução da biodiversidade e especialização produtiva.

No sul do Brasil, em regiões onde predomina a produção de suínos, aves e cereais alimentares, como o oeste e sul catarinense, as experiências das cooperativas descentralizadas já têm em torno de dez anos. São atualmente dezenas de cooperativas espalhadas pelo espaço rural, mesmo nas regiões de mais difícil acesso e periféricas dos centros dinâmicos da economia. Ocupam-se do beneficiamento e/ou industrialização de cereais, produtos cárneos e lácteos, além de hortifrutigranjeiros. Focar-se-á, a seguir, na sua caracterização.

Ao mencionar as cooperativas descentralizadas, faz-se inferência a um tipo especial de inovação organizacional que agrupa agricultores familiares em estruturas de serviços, comercialização e/ou industrialização, do tipo agroindústrias rurais familiares, turismo rural, artesanato e prestação de serviços correlatos. Nesse texto, os autores restringiram-se ao padrão de cooperativas presentes em diferentes regiões do Estado de Santa Catarina. Para uma breve menção utilizaremos, a título de referência, textos publicados em Estevam e Mior (2014).

No contexto das cooperativas descentralizadas, a inovação é concebida como apropriação social de uma novidade submetida ao crivo social e ao reconhecimento coletivo, na busca de soluções aos problemas diários, conforme destacado por Schneider e Menezes (2014). Assim, as cooperativas descentralizadas exemplificam inovação como apropriação social de uma novidade.

Tais modelos de cooperativas surgem como alternativas para o armazenamento, processamento, industrialização e comercialização de produtos agrícolas e pecuários, produzidos por agricultores familiares, caracterizando-se como estruturas organizacionais inovadoras, por exemplo, superando desafios de caráter estrutural e de ordem legal, enfrentados por agroindústrias familiares. São estruturas organizacionais constituídas na forma de redes. Assim são definidas as cooperativas descentralizadas:

[...] forma de organização cooperativa que abriga diversos empreendimentos e diversas atividades da agricultura familiar constituída por uma sede e por unidades de produção e/ou filiais da cooperativa de produção agroindustrial localizadas nas propriedades ou nas comunidades rurais dos cooperados... 
Permite a constituição de empreendimentos de agregação de valor de forma descentralizada por meio da formalização por contrato de comodato "cessão e uso" para a cooperativa. Para fins de legalização, as unidades são repassadas à cooperativa através de contrato de comodato (MIOR et al., 2014, p. 30).

Os autores complementam que as cooperativas descentralizadas são:

[...] organizações de agricultores ou grupos de empreendimentos, que tem por objetivo melhorar as condições de inserção socioeconômica e a competitividade dos agricultores familiares no mercado. Portanto, organizações que facilitam a compra de insumos e matéria-prima, a transformação agroindustrial, a comercialização, o compartilhamento de estruturas, logística ou conhecimento, entre outras funções, constituídas na forma de condomínios; cooperativas por produto; cooperativas descentralizadas e suas filiais e unidades de cooperativas; e centrais de cooperativas... A lógica de funcionamento destas cooperativas é a busca de economias de escala nas operações de produção e comercialização (MIOR et al., 2014, p. 30-31).

Portanto, as cooperativas descentralizadas se assemelham às cooperativas virtuais, destinadas a viabilizar a comercialização da produção de agricultores familiares associados, sem, contudo, constituir-se na forma de unidades agroindustriais (MIOR et al., 2014). Em ambos os casos, uma das estratégias de comercialização utilizadas consiste nas feiras livres, dentre tantas outras possíveis. São formas organizacionais legalizadas para extinguir a figura do atravessador, criando uma relação direta entre o produtor e o consumidor, com isto, reduzindo custos desta transação e possibilitando, simultaneamente, maiores ganhos aos produtores e menores preços para os consumidores. Além disso, trata-se de práticas de empreendedorismo individuais ou coletivas. Complementarmente, e não se trata de um propósito de menor importância, pelo contrário, tais tipologias de cooperativas transformam-se em importante instrumento de empoderamento dos agricultores familiares na perspectiva de assumirem o processo produtivo e de distribuição da produção no mercado com mais autonomia. Logo, na dimensão da gestão, trata-se de uma prática que coaduna com a perspectiva do pós-produtivismo.

\subsection{Práticas agrícolas agroecológicas como superação do produtivismo}

O declínio na qualidade de vida rural e a degradação dos recursos naturais associados à agricultura pós Revolução Verde impulsionou a discussão sobre o desenvolvimento sustentável neste meio, tornando a produção agrícola não apenas uma questão técnica, mas um processo condicionado por dimensões ambientais, sociais, culturais, políticas e econômicas, que devem ser compatibilizadas em agroecossistemas sustentáveis (ALTIERI, 2009).

O desafio imediato da nossa geração é transformar a agricultura industrial e iniciar uma transição para sistemas alimentares que não dependam do petróleo, que sejam biodiversos, resilientes às mudanças climáticas e, ao mesmo tempo, fortaleçam a produção doméstica. Dessa forma, a Agroecologia se apresenta como a alternativa mais viável para gerar sistemas capazes de produzir conservando, além de prestar serviços ambientais (ALTIERI e NICHOLLS, 2011).

As interações e sinergismos, obtidos no sistema agroecológico, resultam em diversos benefícios, pois protegem o solo pela contínua cobertura vegetal; assegura constante produção de alimentos, variedade na dieta alimentar; reaproveita os nutrientes garantindo o uso eficaz dos recursos locais; intensifica o controle biológico de pragas 
fornecendo um habitat para os inimigos naturais; aumenta a capacidade de múltiplo uso do território; assegura uma produção sustentável das culturas sem o uso de insumos químicos que possam degradar o ambiente (ALTIERI et al., 1983). Porém, restaurar a saúde ecológica não é o único objetivo da agroecologia. A manutenção dos sistemas tradicionais de conhecimento são relevantes para a agroecologia, desta forma, consideram-se os saberes locais nesse contexto.

Atualmente é visível a diminuição da população rural, tanto do Brasil, passando de 24,4 \% em 1991 para 15,6 \% em 2010 (MAIA e BUAINAIN, 2015), como do mundo, onde atualmente a população rural corresponde a 46,0 \% do total, com expectativa de diminuir para 34,0 \% em 2050 (ONU, 2015). Uma forma de mudar esse panorama é por meio do estímulo à produção agroecológica, integrando estratégias de desenvolvimento que melhorem a qualidade de vida dos pequenos agricultores. Isso ocorre mediante o desenvolvimento de estratégias de subsistência ecologicamente fundamentadas que aumentem a produtividade daqueles agricultores que competem no mercado, por meio do planejamento e promoção de tecnologias de baixo custo de produção, e promovam a geração de renda e trabalho por meio do planejamento de tecnologias apropriadas que aumentem o valor agregado do que é produzido dentro das pequenas propriedades, particularmente na área de processamento de alimentos (ALTIERI, 2009). Assim, insere-se o "aproveitamento" dos saberes locais. Aquelas áreas rurais que mantém uma reserva de formas econômicas baseadas na agricultura tradicional podem ser o melhor espaço para aproveitar as novas oportunidades econômicas (MIOR, 2010). Observa-se, nesse sentido, a oportunidade para a inserção da agricultura agroecológica, uma vez que os processos de mudança rural não devem ser vistos como determinados unicamente pelas forças presentes na globalização do sistema alimentar, e seu estudo deve incluir os processos de reestruturação rural que envolve as dinâmicas sociais e econômicas regionais (MARSDEN et al., 1990).

Nesses aspectos, percebe-se a essência da multifuncionalidade, que pode ser complementada com a inserção da agricultura orgânica. Esta se caracteriza por ser um sistema holístico de gestão da produção que fomenta e melhora a qualidade do agroecossistema (em particular, a biodiversidade), dos ciclos biológicos e da atividade biológica do solo. Os sistemas de produção orgânica se baseiam em normas de produção específicas e precisas, cuja finalidade é obter agroecossistemas que sejam sustentáveis do ponto de vista social, ecológico, técnico e econômico (FAO/OMS, 2001).

A agricultura orgânica é um sistema de produção comprometido com a saúde, a ética e a cidadania do ser humano, visando a contribuir para a preservação da vida e da natureza. Busca utilizar de forma racional, os recursos naturais, empregando métodos de cultivos tradicionais e as mais recentes tecnologias ecológicas (PENTEADO, 2001). Contendo as características do economicamente viável, ambientalmente correto e socialmente justo, a Agricultura Orgânica assume papel fundamental na criação de condições para a permanência do pequeno agricultor no seu ambiente de negócios (CAPORAL e COSTABEBER, 2007).

Nesse sentido, a agricultura orgânica contempla os dois componentes das políticas ligadas à noção de multifuncionalidade. No primeiro, o econômico e social, pela criação do valor agregado e pela geração de empregos. No segundo, o ambiental e territorial, já que a agricultura orgânica tem um impacto positivo sobre o conjunto dos componentes do meio ambiente e sobre a construção de redes ou arranjos produtivos locais que contribuem para a conformação ou consolidação de um território (SCHIMIDT, 2003). 
Dentre os vários movimentos de agricultura alternativa, que surgiram no século 20, a agricultura orgânica teve como base as teorias desenvolvidas por Albert Howard em seu livro "Testamento da Agricultura" (1940). Na obra, o autor destaca que a base da sustentabilidade da agricultura é a conversão da fertilidade do solo, chamando a atenção para o papel fundamental da matéria orgânica, dos microrganismos do solo e para a necessidade de integração entre a produção vegetal e a animal.

A produção de alimentos realizada nesses moldes possui um forte apelo quanto à sustentabilidade, que, aliada à melhoria da renda da população e à maior preocupação com a segurança alimentar, tem estimulado o consumo desses produtos. No ano de 2012, aproximadamente, 43,1 milhões de hectares encontravam-se sob manejo orgânico no mundo, com 2 milhões de produtores envolvidos nessa atividade (WILLER e LERNOUD, 2014). Em 2013, a América Latina possuía 6,6 milhões de hectares produzindo organicamente, correspondendo a $15,0 \%$ da produção mundial. No entanto, esse sistema de produção ocupa apenas $1,1 \%$ das terras agricultáveis da região. A participação do Brasil na produção orgânica ainda é incipiente, uma vez que o país destina apenas 0,7 milhões de hectares para esse tipo de produção (WILLER e LERNOUD, 2014). Mesmo assim, observa-se um crescimento na adesão dos produtores ao mercado de orgânico. Entre janeiro de 2014 e 2015, houve um aumento de 51,7 \%, sendo que a área de produção orgânica no Brasil já chega a quase 750 mil hectares (BRASIL, 2015). No entanto, a Região Sul possui a menor área com produção orgânica no país, ocupando 37,6 mil hectares (MAGALHÃES, 2015). Santa Catarina possui cerca de 6,2 milhões de habitantes, dos quais cerca de 16,0 \% vivem no meio rural (IBGE, 2010). Nesse estado, a economia agrícola está baseada na pequena propriedade de agricultura familiar, que representa $87,0 \%$ dos estabelecimentos e ocupa 44,0 \% da área e 82,0 \% da população ativa no meio rural (IBGE, 2010).

Diversas vantagens da prática da agricultura orgânica pelo pequeno agricultor são abordadas por Campanhola e Valarini (2001), as quais, resumidamente, contempla a viabilidade da produção em pequena escala, visto que, muitas vezes, a comercialização é realizada diretamente nas casas ou em feiras; favorece a diversificação produtiva no estabelecimento; há necessidade de maior mão de obra (estímulo à geração de empregos); menor dependência de insumos externos (aproveitamento dos recursos disponíveis na propriedade, como exemplo, a compostagem); eliminação do uso de agrotóxicos e maior valor comercial dos produtos.

Mesmo com todo esse panorama vantajoso ao produtor de orgânicos, na prática, alguns problemas ainda dificultam sua inserção e ou permanência nessa atividade. A falta de informação e assistência técnica eficaz para atender às demandas desse setor produtivo e a defasagem em pesquisas técnicas para solucionar problemas básicos fazem com que o produtor de orgânicos, muitas vezes, fique desamparado. Mesmo que tenha ocorrido um maior aporte de recursos do Estado para o fortalecimento da agricultura familiar, ainda são insuficientes para suprir a demanda. Dessa forma, Bonnal e Maluf (2009) destacam a reorganização dos movimentos sociais agrícolas e rurais, com capacidade de negociação com o poder público, além da participação das ONGs na representação desse setor e articulação junto aos órgãos governamentais, como incentivadoras para geração de políticas voltadas a esse setor.

\subsection{Os Sistemas Agroflorestais como estratégia de superação do produtivismo}

Os Sistemas Agroflorestais -SAF são, em essência, sistemas de uso da terra que integram espécies perenes lenhosas com culturas agrícolas e/ou pecuária em arranjos espaciais e temporais (MAY e TROVATTO, 2008). Assim, há uma grande diversidade 
de combinações e possibilidades sob a designação de "sistemas agroflorestais" que diferem quanto aos arranjos estruturais (espacial e temporal), fisionomia, composição florística, manejo do sistema, aspectos ecológicos e características socioeconômicas predominantes (ENGEL, 1999; MAY e TROVATTO, 2008). Vários são os benefícios desse tipo de cultivo. Ao otimizarem o uso da terra e proporcionarem simultaneamente benefícios biológicos e socioeconômicos, os SAFs são apontados como sistemas sustentáveis promissores para solução de problemas no uso dos recursos naturais (NAIR, 2007).

Entre os benefícios ambientais dos sistemas agroflorestais, destacam-se o fornecimento de habitat para espécies que toleram certos níveis de distúrbios; fornecem alternativa mais produtiva e sustentável aos sistemas convencionais de exploração dos recursos naturais; constituem corredores ecológicos, trampolins ou zonas de amortecimento, favorecendo a conservação de espécies sensíveis da flora e fauna; fornecem serviços ecossistêmicos como sequestro de carbono, melhoria da qualidade do ar, da água e do solo, além da conservação da biodiversidade (NAIR, 2007; MAY e TROVATTO, 2008).

Os benefícios socioeconômicos reconhecidos decorrem principalmente da alternância e diversificação da produção, do (re)aproveitamento dos recursos intrínsecos aos sistema e do maior envolvimento dos agricultores com o sistema de produção (NAIR, 2007; YAMADA e GHOLZ, 2002; MAY e TROVATTO, 2008).

Apesar dos reconhecidos benefícios proporcionados pelos SAFs, o setor enfrenta inadequada disseminação do conhecimento, falta de incentivos, restrições legais e a falta de coordenação entre setores governamentais para os quais os SAFs contribuem: agricultura, silvicultura, desenvolvimento rural, meio ambiente e comércio (FAO, 2013).

De acordo com Altieri e Nicholls (2011), os SAFs aumentam a multifuncionalidade da agricultura em muitas comunidades, contribuindo não só para a soberania alimentar e produtiva de milhares de famílias, mas também para a economia comunitária e a proteção da biodiversidade. Esses sistemas têm demonstrado resiliência a eventos climáticos extremos. Além de que a propagação de SAFs de base agroecológica pode ter impacto positivo na subsistência, resiliência e soberania das comunidades agrícolas. O sucesso vai depender do uso de um conjunto de práticas que, além da diversificação de produtos, favoreçam o melhor uso dos recursos locais e valorizem o capital humano por meio de capacitações (ALTIERI e NICHOLLS, 2011).

\subsection{Especificação de ativos e recursos territoriais como estratégias de valorização da qualidade e identidade territorial dos produtos}

Enquanto as práticas produtivistas almejam, sobremaneira, a produção e a produtividade, privilegiando a intensificação, a concentração e a especialização, implicando no uso intensivo dos solos, cujas consequências sociais e ambientais são extremamente preocupantes, as práticas pós-produtivistas se propõem, dentre outros aspectos, a diminuir a poluição ambiental, restaurar os habitats naturais, diversificar a produção e prestigiar a qualidade. Desse modo, urge a necessidade de viabiliza-se práticas de gestão inovadoras no setor agrário, que atentem aos anseios da sociedade moderna, refletidos no sistema pós-produtivista.

Dentre outras tantas, a estratégia de especificação dos ativos e recursos territoriais, como o exemplo da Indicação Geográfica ${ }^{5}$, contribui para superar práticas

\footnotetext{
${ }^{5}$ A abordagem deste tema não será aqui aprofundada. Sugerimos algumas obras: Anjos, Criado e Caldas, 2013; Dallabrida, 2014; Froehlich, 2012; Niederle, 2013.
} 
produtivistas de produção em massa de commodities. A principal estratégia, neste sentido, é o reconhecimento da reputação e especificidade territorial de produtos oriundos de territórios inovadores, no sentido de qualificar a produção, competir no mercado pela qualidade e o diferencial dos produtos.

Sobre as diferentes questões relacionadas à prospecção e gestão de experiências de Indicação Geográfica, Vandecandelaere et al. (2011) referem-se aos processos de valorização de produtos com qualidade específica vinculada a sua origem geográfica, ressaltando que a efetividade depende da existência de três requisitos prévios: (1) o produto, que precisa apresentar características específicas vinculadas à origem geográfica, que lhe atribuem uma qualidade e uma reputação especiais, reconhecidas no mercado e com demanda entre os consumidores; (2) o território, cujas características especiais de qualidade são o resultado dos recursos humanos e/ou naturais da área de produção; (3) as pessoas, como os produtores locais, que herdaram tradições e saber fazer próprios, os quais devem estar motivados e capacitados para desencadear práticas de criação e preservação de valor a determinados produtos com especificidade.

No entanto, as experiências de Indicação Geográfica, apesar de se apresentarem como uma estratégia inovadora e com potencial para contribuir no desenvolvimento dos territórios atingidos, em especial em práticas agrícolas da agricultura familiar, as mesmas apresentam desafios de todas as espécies. Estudos realizados em experiências brasileiras de Indicação Geográfica já constataram inúmeros problemas. Um dos mais recorrentes é o fato de que no processo de organização para seu reconhecimento e mesmo após o mesmo, as instituições articuladoras falharam na forma de envolvimento dos diferentes segmentos da cadeia produtiva. É comum o fato de ter sido envolvido apenas parte dos produtores, ou mesmo a falta de um bom processo de sensibilização. Noutros casos, uma ou poucas empresas ligadas ao setor produtivo lideraram o processo, ficando evidente prevalecer interesses individualizados, em prejuízo do coletivo, a ponto de possibilitar uma conclusão indesejável: o recurso ao associativismo e à diferenciação, por vezes, não passa de uma estratégia que viabiliza negócios lucrativos privados (DALLABRIDA, 2016) ${ }^{6}$.

Apesar disso, a estratégia de reconhecimento da especificidade e reputação de determinados produtos por meio de estratégias como a Indicação Geográfica tem o potencial de valorização dos produtos oriundos da agricultura familiar, utilizando a qualificação, a diferenciação e a agregação de valor aos produtos como diferencial de inserção no mercado consumidor. Logo, a Indicação Geográfica pode ser considerada um avanço na perspectiva de práticas inovadoras no espaço rural, além de servir como forma de ampliação da autonomia dos produtores rurais.

\subsection{Por fim, a necessidade de superação da dimensão de subalternidade territorial, rumo ao território-rede}

Finaliza-se esta abordagem teórica com uma alusão à necessidade de superação das práticas de subalternidade na ação coletiva nos territórios. Uma contribuição, nesse sentido, vem de Covas e Covas (2014a, p. 32), afirmando que avanços nos territórios subalternos, na busca de uma territorialidade com mais autonomia, implica em construir "sistemas territoriais complexos e inteligentes", o que consiste em "[...] transitar de uma cultura-zona de territorialidade homogênea, para uma cultura-rede de multiterritorialidade [...]". Segundo, a contribuição de Pecqueur (2005), para o qual a

\footnotetext{
${ }^{6}$ Em relação à qualificação da prática em experiências de Indicação Geográfica, Dallabrida (2016b) se propõe contribuir apresentando indicativos metodológicos para avaliação de experiências, para, então, saber em quais aspectos é necessário interagir a fim de avançar.
} 
cesta de bens e serviços territorializados precisaria atender aos seguintes parâmetros: (1) um conjunto de bens e serviços complementares que reforce a imagem mercadológica do local; (2) uma combinação de bens privados e públicos que contribuam para elaborar a imagem e reputação do território; (3) uma combinação interativa entre os produtores da cesta (clube) a fim de internalizar a renda da qualidade territorial. $O$ fornecimento de mercadorias da cesta poderia se constituir em objetivo estratégico para as políticas públicas de desenvolvimento local ${ }^{7}$.

Por fim, manifesta-se o posicionamento sobre desenvolvimento, pois entende-se que, em sua formulação, há elementos indicativos de dinâmicas territoriais que atendem à perspectiva pós-produtivista.

\begin{abstract}
O desenvolvimento territorial é entendido como um processo de mudança continuada, situado histórica e territorialmente, mas integrado em dinâmicas intraterritoriais, supraterritoriais e globais, sustentado na potenciação dos recursos e ativos (materiais e imateriais, genéricos e específicos) existentes no local, com vistas à dinamização socioeconômica e à melhoria da qualidade de vida da sua população (DALLABRIDA, 2015a, p. 325).
\end{abstract}

Dentre os elementos constitutivos da concepção sobre desenvolvimento territorial destacada, dois merecem destaque. Primeiro, o fato de que os recursos e ativos territoriais são a base. Segundo, que o fim seja a melhoria da qualidade de vida da população.

\title{
5 Considerações finais
}

As práticas produtivistas, consideradas adequadas no passado, ainda se encontram plenamente vigentes. Não obstante os avanços científicos e tecnológicos (nos campos teórico e experimental) expandirem continuamente as fronteiras do conhecimento, as práticas produtivistas permaneceram, destoando das revoluções vivenciadas nas mais distintas áreas da atividade humana. Contudo, as mudanças se impõem inexoravelmente e, no espaço rural, novas demandas propiciaram o advento das práticas pós-produtivistas, ainda em incipiente adoção.

Enquanto as práticas produtivistas almejam, sobremaneira, a produção e a produtividade, privilegiando a intensificação, a concentração e a especialização, implicando no uso intensivo dos solos, cujas consequências sociais e ambientais são extremamente preocupantes, as práticas pós-produtivistas se propõem, dentre outros aspectos, a diminuir a poluição ambiental, restaurar os habitats naturais, diversificar a produção, prestigiar a qualidade e ampliar a autonomia dos atores territoriais. Desse modo, surge a necessidade de viabilizar-se práticas de gestão inovadoras no setor agrário, que atentem aos anseios da sociedade moderna, refletidos no sistema pósprodutivista. A referência feita às cooperativas descentralizadas é um bom exemplo.

Muitos avanços, nesse sentido, já foram conseguidos. No entanto, pela facilidade de trabalho e ganhos financeiros rápidos que o sistema produtivista trouxe, atualmente há resistência na inserção do sistema pós-produtivista em algumas propriedades. Mas, a recente preocupação com a segurança alimentar impulsiona o crescimento de mercados diferenciados, como o orgânico e agroecológico, os quais atendem a uma parcela dos consumidores exigentes, que não abrem mão dos benefícios que esses sistemas de produção trazem a saúde e ao meio ambiente.

\footnotetext{
${ }^{7}$ Ver aprofundamento do tema em Covas e Covas (2014b).
} 
Por fim, as práticas pós-produtivistas, infelizmente, ainda se apresentam muito mais como perspectivas do que realidades. No entanto, tais perspectivas são caminhos para reacender possibilidades de novas práticas e novas realidades.

\section{REFERÊNCIAS}

ABRAMOVAY, R. A dualização como caminho para a agricultura sustentável. Estudos Econômicos, v. 24, $\mathrm{n}^{\circ}$ especial, p.157-182, 1994.

ALTIERI, M. A. Agroecologia: A dinâmica produtiva da agricultura sustentável. Porto Alegre: UFRGS, 2009. 120 p.

ALTIERI, M. A.; LETOURNEAU, D. K.; DAVIS, J. R. Developing sustainable agroecosystems. BioScience, Califórnia, v.33, n. 1, p.45-49, 1983.

ALTIERI, M. A.; NICHOLLS, C. I. O potencial Agroecológico dos Sistemas Agroflorestais na América Latina. Revista Agriculturas: experiências em Agroecologia, v. 8, n. 2, p.31-34, 2011.

ANJOS, F. S.; CRIADO, E. A.; CALDAS, N. V. Indicações geográficas e desenvolvimento territorial: um diálogo entre a realidade europeia e brasileira. Dados [online], vol. 56, n. 1, p. 207-236, 2013.

ARMESTO LÓPEZ, X. A. Notas teóricas en torno al concepto de Postproductivismo Agrario. Investigaciones Geográficas, Alicante, n. 36, p.137-156, 2005.

BERGSTROM, J. Postproductivism and rural land values. In: Conference on Land Use Conflicts and Problems sponsored by the Northeast Regional Center for Rural Development, 2002, Orlando, February 2002.

BJÖRKHAUG, H.; RICHARDS, C. A. Multifunctional agriculture in policy and practice? A comparative analysis of Norway and Australia. Journal of Rural Studies, v. 24, 98-111, 2007.

BONNAL, P.; CAZELLA, A. A.; MALUF, R. S. Multifuncionalidade da agricultura e desenvolvimento territorial: avanços e desafios para a conjunção de enfoques. Estudos Sociedade e Agricultura (UFRJ), v. 16, p. 185-227, 2008.

BONNAL, P.; MALUF, R. S. Políticas de desenvolvimento territorial e multifuncionalidade da agricultura familiar no Brasil. Politica \& Sociedade, v. 8, p. 211$250,2009$.

BRASIL. MINISTÉRIO DA AGRICULTURA. Número de produtores orgânicos cresce $51,7 \%$ em um ano. Disponível em $<$ http://www.agricultura.gov.br/comunicacao/noticias/2015/03/numero-de-produtoresorganicos-cresce-51 porcento-em-um-ano>. Acesso em 17 ago. 2015.

CAMPANHOLA, C.; VALARINI, P. J. A agricultura orgânica e seu potencial para o pequeno agricultor. Cadernos de Ciência \& Tecnologia, Brasília, v. 18, n. 3, p. 69-101, set-dez. 2001. 
CAPORAL, F. R; COSTABEBER, J. A. Agroecologia e extensão rural: contribuições para a promoção do desenvolvimento rural sustentável. Brasília: MDA/SAF/DATER, 2004, 166 p.

CAZELlA, A. A.; BONNAL, P.; MALUF, R. S. J. (Orgs.). Agricultura familiar: multifuncionalidade e desenvolvimento territorial no Brasil. 1. ed. Rio de Janeiro: Mauad, 2009. v. 1. 301 p.

CAZELlA, A. A.; ROUX, B. Agribusiness em questão: a emergência da agricultura multifuncional. Estudos Sociedade e Agricultura, Rio de Janeiro, v. 13, p. 46-69, out. 1999.

COVAS, A. M.; COVAS, M. M. C. M. A construção social dos Territórios-Rede: A inteligência territorial da $2^{a}$ ruralidade. São Paulo: LiberArs, 2014b (disponível no formato E-book). 271 p.

COVAS, A. M.; COVAS, M. M. C. M. Os territórios-rede: a inteligência territorial da $2^{a}$ ruralidade. Lisboa: Editora Colibri, 2014a. 230 p.

DALLABRIDA, V. R. (Org.). Desenvolvimento Territorial: Políticas públicas brasileiras, experiências internacionais e a Indicação Geográfica como referência. São Paulo: LiberArs, 2014. 289 p.

DALLABRIDA, V. R. Ativos Territoriais, Estratégias de Desenvolvimento e Governança Territorial: uma análise comparada de experiências brasileiras e portuguesas. Revista EURE, Santiago de Chile, n. 126, maio/2016a.

DALLABRIDA, V. R. Governança territorial: do debate teórico à avaliação da sua prática. Análise Social, v. L(2º, n. 215, p. 304-328, 2015 a.

DALLABRIDA, V. R. Território, Governança e Desenvolvimento Territorial: indicativos teórico-metodológicos, tendo a indicação geográfica como referência. São Paulo: LiberArs, 2016b. 101 p.

DALLABRIDA, V. R.; BENEDETTI, E. L.; TOMPOROSKI, A. A. Do Produtivismo, ao Neoprodutivismo, para o Pós-Produtivismo no Espaço Rural: contextualização do debate teórico e possibilidades de práticas inovadoras em territórios catarinenses. $1^{\circ}$ Seminário Nacional de Desenvolvimento Regional, FACCAT, Taquara, Anais..., 31-03 a $01-04 / 2016$.

DUFUMIER, M.; COUTO, V. A. Neoprodutivismo. Caderno CRH, Salvador, n. 28, p. 81-112, 1998.

ENGEL, V. L. Introdução aos Sistemas Agroflorestais. Botucatu: FEPAF. 1999. 70 p.

ESTEVAM, D. O.; MIOR, L. C. Inovações na Agricultura Familiar: as cooperativas descentralizadas em Santa Catarina. Florianópolis: Editora Insular, 2014. 295 p.

EVANS, N. J.; ILBERY, B. W. The pluriactivity, part-time farming, and farm diversification debate. Environment and Planning A, v. 25, p. 945-959, 1993. 
EVANS, N.; MORRIS, C.; WINTER, M. Conceptualizing agriculture: a critique of post-productivism as the new orthodoxy. Progress in Human Geography, v. 26, p. 313332, 2002.

FAO. Advancing Agroforestry on the Policy Agenda: A guide for decision-makes. [S. I.]: Food and Agriculture Organization of the United Nations, 2013.

FAO/OMS. Directrices para la Producción, Elaboración, Etiquetado y Comercialización de Alimentos Producidos Orgánicamente. Publicado por la Secretaría del Programa Conjunto FAO/OMS sobre Normas Alimentarias, FAO, Roma, 2001. Disponível em: http://www.fao.org/docrep/005/y2772s/y2772s02.htm\#bm02. Acesso em 21 mar. 2016.

FROEHLICH, J. M. (Org.). Desenvolvimento Territorial: Produção, Identidade e Consumo. Ijuí (RS): Editora UNIJUI, p. 226, 2012. 424 p.

IBGE - Instituto Brasileiro de Geografia e Estatística. Censo 2010. Disponível em: http://cidades.ibge.gov.br/xtras/temas.php?lang=\&codmun=421830\&idtema=16\&searc $\mathrm{h}=$ santa-catarina. Acesso em 17 mar. 2016.

IBGE-INSTITUTO BRASILEIRO DE GEOGRAFIA E ESTATÍSTICA. Produção Agrícola Municipal. Disponível em: $<$ http://www.sidra.ibge.gov.br/bda/tabela/listabl.asp?c=106\&z=p\&o=28>. Acesso em 08 maio 2015.

ILBERY, B. W.; BOWLER, I. From agricultural productivism to postproductivism. In: ILBERY, B. (Ed.). The Geography of Rural Change. Longman: Harlow, p. 57-84, 1998.

KNICKEL, K. Agricultural structural change: impact on the rural environment. Journal of Rural Studies, v.6, p.383-393, 1990.

LAMINE, C. Sustainability and Resilience in Agrifood Systems: Reconnecting Agriculture, Food and the Environment. Sociologia Ruralis, v. 55, n. 1, p. 41-61, 2015.

LANDAIS, E. Agriculture durable: les fondements d'un nouveau contrat social? In: Courier de l'environnement de l'INRA, INRA, Paris, n. 33, p. 5-22, 1998.

LOWE, P.; MURDOCH, J.; MARSDEN, T.; MUNTON, R.; FLYNN, A. regulating the new rural spaces: the uneven development of land. Journal of Rural Studies, v. 9, p. 205-222, 1993.

MAGALHÃES, R. Número de produtores orgânicos cresce 51,7\% em um ano. Ministério da Agricultura. 2015.2 Disponível em: <http://www.agricultura.gov.br/comunicacao/noticias/2015/03/numero-de-produtoresorganicos-cresce-51 porcento-em-um-ano>. Acesso em 20 mar. 2016.

MAIA, A. G.; BUAINAIN, A. M. O novo mapa da população rural brasileira. Confins Revista Franco brasileira de geografia [online], n. 25, 2015.

Disponível em: 〈https://confins.revues.org/10548?lang=pt〉. Acesso em 22 mar. 2016. 
MARSDEN, T.; LOWE, P.; WHATMORE, S. Rural restructuring: global processes and their responses (critical perspectives on rural change). Londres: David Fulton Publishes, p.21-44, 1990.

MATHER, A. S.; HILL, G.; NIJNIK, M. Post-productivism and rural land use: cul de sac or challenge for theorization? Journal of Rural Studies, v. 22, p. 441-455, 2006.

MAY, P. H.; TROVATTO, C. M. M. Manual Agroflorestal para a Mata Atlântica. Brasília: Ministério do desenvolvimento Agrário, Secretaria da Agricultura familiar, 2008, 196 p.

MIOR, L. C. Agricultura familiar, agroindústria e desenvolvimento territorial. In: VIEIRA, P. F.; CAZELLA, A.; CERDAN, C.; CARRIÈRRE, J. P. Desenvolvimento Territorial Sustentável no Brasil. Subsídios para uma política de fomento. Florianópolis: APED: Secco. 2010, p. 235-257.

MIOR, L. C. et al. Inovações organizacionais da agricultura familiar no Sul Catarinense. In: ESTEVAM, D. O.; MIOR, L. C. Inovações na Agricultura Familiar: as cooperativas descentralizadas em Santa Catarina. Florianópolis: Insular, 2014, p. 21-53.

NAIR, P. K. R. Perspective The coming of age of agroforestry. Journal of the Science of Food and Agriculture. v. 87, p.1613-1619, 2007.

NIEDERLE, P. A. (Org.). Indicações Geográficas: qualidade e origem nos mercados alimentares. 1. ed. v. 1. Porto Alegre: UFRGS, 2013. 296 p.

ONU- Organização das Nações Unidas. Centro regional de Informação das Nações Unidas. Relatório da ONU mostra população mundial cada vez mais urbanizada, mais de metade vive em zonas urbanizadas ao que se podem juntar 2,5 mil milhões em 2050. Disponível em: http://www.unric.org/pt/actualidade/31537-relatorio-da-onu-mostrapopulacao-mundial-cada-vez-mais-urbanizada-mais-de-metade-vive-em-zonas-

urbanizadas-ao-que-se-podem-juntar-25-mil-milhoes-em-2050. Acesso em 22 mar. 2016.

PENTEADO, S. R. Agricultura orgânica. (Série Produtor Rural, Edição Especial). Piracicaba: ESALQ, 2001. 41 p.

PLOEG, J. D. et al. Rural Development: From Practices and Policies towards Theory. Sociologia Ruralis, v. 40, n. 4, p. 391-408, 2000.

PULPÓN, Á. R. R. Producción agroalimentaria de calidad y postproducctivismo agrario: El caso de los vinos de pago en Castilla-La Mancha. Anales de Geografía, v. 33, n. 2, p. 137-154, 2013.

ROCHE, M.; ARGENT, N. The fall and rise of agricultural productivism? An Antipodean viewpoint. Progress in Human Geography, v. 39, p. 621-635, 2015.

SCHIMIDT, W. Conversão à agricultura orgânica e multifuncionalidade: o caso das Encostas da Serra Geral (SC). In: CARNEIRO, M. J.; MALUF, R. S. (Orgs.) Para além 
da produção: multifuncionalidade e agricultura familiar. Rio de Janeiro: MUAD, 2003, p. 44-60.

SCHNEIDER, S.; MENEZES, M. A. Inovação e atores sociais. In: SCHNEIDER, S. et al. (Orgs.). Sementes e brotos da transição: inovação poder e desenvolvimento em áreas rurais do Brasil. Porto Alegre: Editora da UFRGS, p. 11-17, 2014.

TRICHES, R. M.; SCHNEIDER, S. Alimentação, sistema agroalimentar e os consumidores: novas conexões para o desenvolvimento rural. Cuadernos de Desarrolo Rural, v. 75, p. 55-75, 2015.

VIEIRA, P. H. F.; CAZELlA, A. A.; CERDAN, C.; CARRIÈRE, J. (Orgs.). Desenvolvimento Territorial Sustentável no Brasil: subsídios para uma política de fomento. 1. ed. Florianópolis: APED: Secco, 2010. v. 1. 487 p.

WARD, N.; JACKSON, P.; RUSSELL, P. WILKINSON, K. Productivism, PostProductivism and European Agricultural Reform: The Case of Sugar. Sociologia Ruralis, v. 48, n. 2, p. 118- 132, 2008.

WILLER, H.; LERNOUD, J. The World of Organic Agriculture. Statistics and Emerging Trends. International Federation of Organic Agriculture Movements (IFOAM) \& Research Institute of Organic Agriculture (FiBL). 2014. Disponível em: $<$ https://shop.fibl.org/de/artikel/c/statistik/p/1636-organic-world-2014.html>. Acesso em 22 mar. 2016.

WILSON, G. A. From productivism to post-productivism... and back again? Exploring the (un)changed natural and mental landscapes of European agriculture. Transactions of the Institute of British Geographers, n. 26, p. 77-102, 2001.

YAMADA, M.; GHOLZ, H. L. An evaluation of agroforestry systems as a rural development option for the Brazilian Amazon. Agroforestry Systems, v. 55, p. 81-87, 2002.

Submetido em 30/05/2016

Aprovado em 27/07/2016

\section{Sobre os Autores}

Valdir Roque Dallabrida

Geógrafo, doutor em Desenvolvimento Regional, professor e pesquisador com atuação no Mestrado em Desenvolvimento Regional da Universidade do Contestado (Santa Catarina - Brasil).

E-mail: valdirdallabrida@gmail.com.

\section{Eliziane Luiza Benedetti}

Agrônoma, doutora em Solos e Nutrição de Plantas, professora e pesquisadora do Instituto Federal de Santa Catarina (Campus Canoinhas-SC), atualmente, pós-doutoranda no Mestrado em Desenvolvimento Regional da Universidade do Contestado.

E-mail: eliziane.benedetti@ifsc.edu.br. 